\title{
Effect of Silica on Formation of Porous Alumina during Unidirectional Solidification in Hydrogen Atmosphere
}

\author{
S. Ueno, L. M. Lin* and H. Nakajima \\ The Institute of Scientific and Industrial Research, Osaka University, Ibaraki 567-0047, Japan
}

A porous alumina with cylindrical pores was fabricated by unidirectional solidification in pressurized $\mathrm{H}_{2}$ or $\mathrm{H}_{2}$-Ar mixed gases using alumina feed rod with $15 \% \mathrm{SiO}_{2}-\mathrm{Al}_{2} \mathrm{O}_{3}$ composition. The effect of silica additive on the formation of pores during the solidification was investigated. The porosity of the samples increases with increasing hydrogen partial pressure under a fixed total pressure and decreases with increasing total pressure under a fixed hydrogen partial pressure. No cylindrical pores are formed under $10 \% \mathrm{H}_{2}-90 \% \mathrm{Ar}$ atmosphere. On the other hand, when the solidification is performed under $50 \% \mathrm{H}_{2}-50 \% \mathrm{Ar}$ or $100 \% \mathrm{H}_{2}$ atmosphere, the porosity and pore size for porous alumina fabricated using $15 \% \mathrm{SiO}_{2}-\mathrm{Al}_{2} \mathrm{O}_{3}$ feed rod are larger than those for the samples fabricated using $99.99 \% \mathrm{Al}_{2} \mathrm{O}_{3}$ feed rod. $\mathrm{Many}_{\mathrm{small}}$ facet shape pores are formed due to vaporization of silica component on the cooling step during the solidification. When a solidification is performed under $10 \% \mathrm{H}_{2}-90 \% \mathrm{Ar}$ atmosphere using $15 \% \mathrm{SiO}_{2}-\mathrm{Al}_{2} \mathrm{O}_{3}$ feed rod, an excess hydrogen atom in the solid phase is lack to make the cylindrical pores due to decreasing the hydrogen solubility in solid phases by silica addition then, non-porous alumina is formed. As a result, the porosity for porous alumina fabricated using $15 \% \mathrm{SiO}_{2}-\mathrm{Al}_{2} \mathrm{O}_{3}$ feed rod is not proportional to square root of hydrogen partial pressure under a fixed total pressure. [doi:10.2320/matertrans.MRA2008413]

(Received March 9, 2009; Accepted May 12, 2009; Published July 1, 2009)

Keywords: porous alumina, unidirectional solidification, floating zone method

\section{Introduction}

Porous alumina has been used as hot gas or molten metal filters and catalyst carriers because of their excellent mechanical properties and high thermal and chemical stabilities. ${ }^{1)}$ Since the filters and catalyst carriers are subjected in a liquid or gas flow, open porous structure is suitable to use as filters and carriers. Several groups proposed the fabrication processes of porous alumina with open porous structure. Zhang et al. fabricated porous alumina with unidirectionally aligned continuous pores via the slurry coating of fugitive cotton fiber. ${ }^{2)}$ Ding et al. prepared a porous alumina with oriented pores by combining a foaming method with sol-gel technology. ${ }^{3)}$ Isobe et al. prepared porous alumina with oriented cylindrical pores by an extrusion method. ${ }^{4)}$ The present authors also proposed a fabrication method for a porous alumina with cylindrical pores by unidirectional solidification in pressurized hydrogen atmosphere. ${ }^{5)}$ In this method, insoluble hydrogen atom in solid phase released at the solid-liquid interface during the unidirectional solidification and then, cylindrical pores were elongated in the solidification direction. ${ }^{5)}$ The pore morphologies such as porosity, average pore size and pore distribution can be controlled by silica and calcia addition in the feed rod. ${ }^{6-8)}$ Especially, the porosity of the solidified alumina drastically increased from $10 \%$ to $30 \%$ by $20 \%$ of silica addition in the alumina feed rod. ${ }^{8)}$ However, no further details on the mechanism of the increase porosity by silica addition were clear. On the application of porous alumina with directional pores for filters, high porosity is required. Silica addition is an useful method for the fabrication of porous alumina with high porosity in the unidirectional solidification method proposed by the present authors. ${ }^{5)}$

*Graduate Student, Osaka University, Present address: Komatsu Ltd., Tokyo 107-8414, Japan
The present paper reports the effect of silica additive on the formation of pores in alumina during unidirectional solidification in hydrogen atmosphere in order to elucidate the mechanism of increase of porosity by silica addition.

\section{Experimental Procedure}

For the preparation of $15 \% \mathrm{SiO}_{2}-\mathrm{Al}_{2} \mathrm{O}_{3}$ feed rod, high purity alumina $(99.99 \%$ purity, Sumitomo Chemical Co. Ltd.) and silica (99.8\% purity, Admatechs Co. Ltd.) powders were used as starting materials. An appropriate molar ratio of alumina and silica powders was mixed with a binder in water and the slurry was poured into the mold. After drying in air, calcination was performed at $1473 \mathrm{~K}$ for $7.2 \mathrm{ks}$ in air and then, $15 \% \mathrm{SiO}_{2}-\mathrm{Al}_{2} \mathrm{O}_{3}$ feed rod with $8 \mathrm{~mm}$ diameter and $150 \mathrm{~mm}$ length was prepared.

The unidirectional solidification was performed using optical floating zone apparatus in pressurized hydrogen gas; $100 \% \mathrm{H}_{2}$ gas, $50 \% \mathrm{H}_{2}-50 \% \mathrm{Ar}$ mixed gas or $10 \% \mathrm{H}_{2}-90 \% \mathrm{Ar}$ mixed gas was used as environmental gas. The total pressure was controlled in the range from 0.2 to $0.8 \mathrm{MPa}$. A xenon lamp was used as an optical source. The xenon lamp put on one side of the focus in the elliptical mirror and the melting of the $15 \% \mathrm{SiO}_{2}-\mathrm{Al}_{2} \mathrm{O}_{3}$ was performed on another focus. The feed rod was hooked on upper shaft and another feed rod was fixed with lower shaft. The feed rods and the melting zone were set up in a quartz tube. The transference velocity of the melting zone was fixed to $56 \mu \mathrm{m} / \mathrm{s}$ and for the homogeneous heating of the feed rod, the feed rods was turned over with the rod rotation rate of $20 \mathrm{rpm}$ during the experiment.

The solidified samples cut parallel and perpendicular to the solidification direction by Step Cutter (MARUTO, MC-170Y). The cross-sections parallel and perpendicular to the solidification direction of the solidified samples were observed by SEM (JEOL, JSM-6360T). The porosity was 


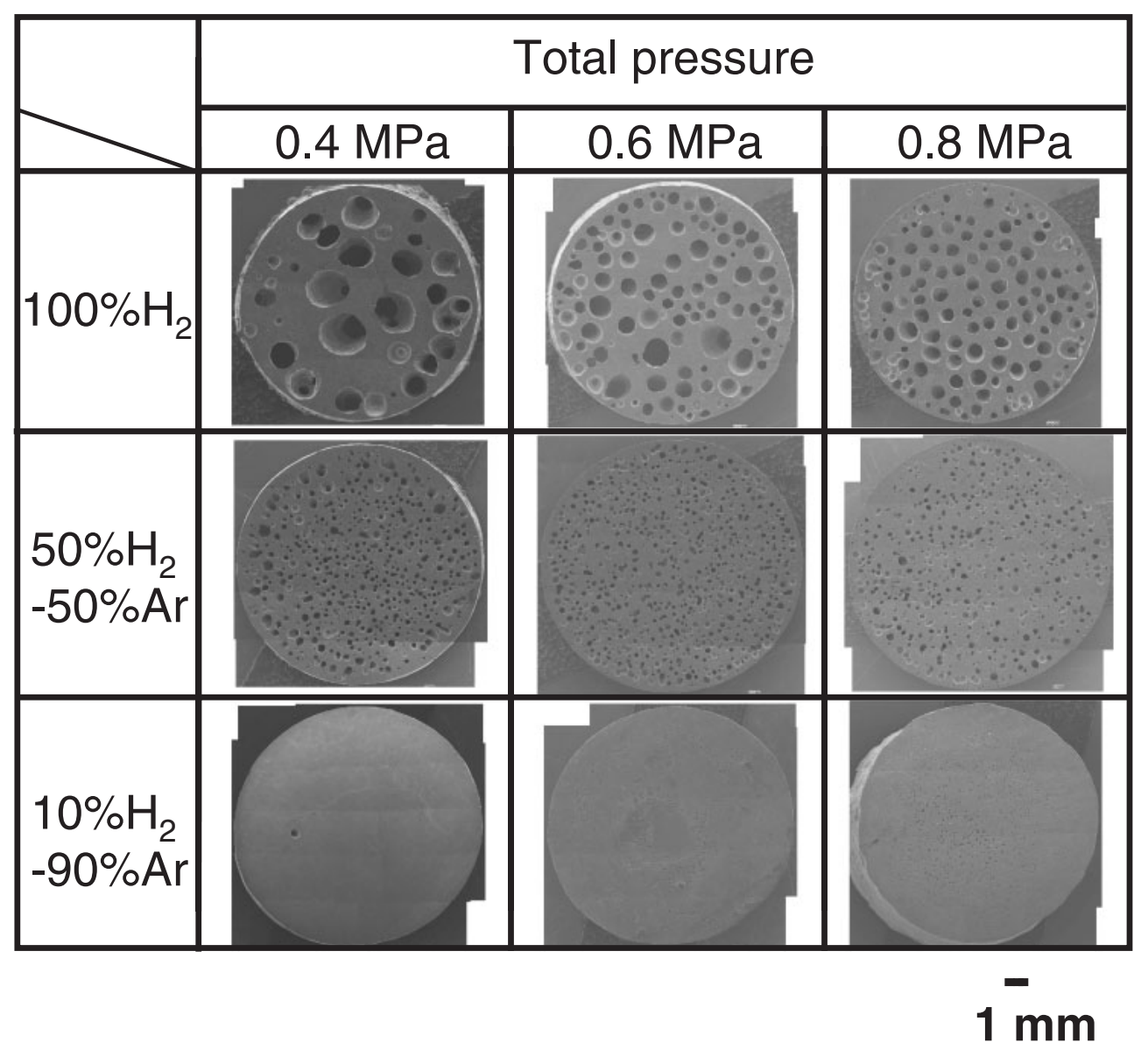

Fig. 1 Cross section perpendicular to the solidification direction of the samples fabricated using $15 \% \mathrm{SiO}_{2}-\mathrm{Al}_{2} \mathrm{O}_{3}$ feed rod in pressurized $100 \% \mathrm{H}_{2}, 50 \% \mathrm{H}_{2}-50 \% \mathrm{Ar}$ and $10 \% \mathrm{H}_{2}-90 \% \mathrm{Ar}$ atmosphere. The total pressure was changed by $0.4,0.6$ and $0.8 \mathrm{MPa}$.

calculated by computer program WinRoof (ver. 5, Mitani Co. Ltd.) using images of the cross section perpendicular to the solidification direction.

\section{Results and Discussion}

Figure 1 shows the cross section perpendicular to the solidification direction of the samples fabricated in pressurized $100 \% \mathrm{H}_{2}, 50 \% \mathrm{H}_{2}-50 \% \mathrm{Ar}$ or $10 \% \mathrm{H}_{2}-90 \% \mathrm{Ar}$ using $15 \% \mathrm{SiO}_{2}-\mathrm{Al}_{2} \mathrm{O}_{3}$ feed rod. The porosity decreases with increasing total pressure and increases with increasing hydrogen partial pressure. This tendency is same to that of the porous alumina fabricated using $99.99 \% \mathrm{Al}_{2} \mathrm{O}_{3}$ feed rod as in our previous report. ${ }^{5)}$ However, in the case of the samples fabricated in $10 \% \mathrm{H}_{2}-90 \% \mathrm{Ar}$ in the present study, no porous structure is formed.

Figure 2(a) and (b) show the porosity change with hydrogen partial pressure for the samples fabricated using $99.99 \% \mathrm{Al}_{2} \mathrm{O}_{3}$ feed rod and $15 \% \mathrm{SiO}_{2}-\mathrm{Al}_{2} \mathrm{O}_{3}$ feed rod. The result of the samples fabricated using $99.99 \% \mathrm{Al}_{2} \mathrm{O}_{3}$ feed rod was taken from our previous work. ${ }^{5)}$ According to the result by Serra et al., ${ }^{9)}$ the hydrogen solubility in solid alumina phase obeys Sieverts' law and proportional to square root of hydrogen partial pressure. ${ }^{9)}$ No data for hydrogen solubility in liquid alumina phase is available. Assuming the hydrogen solubility in liquid alumina phase is proportional to square root of hydrogen partial pressure and the hydrogen solubility in the solid is negligibly smaller than that in the liquid, the amount of solubility gap between solid and liquid phases at the melting point is also proportional to square root of hydrogen partial pressure. Since, in the steady state of the unidirectional solidification, the concentration of hydrogen atom in the solid phase near the solid-liquid interface can be considered as a fixed value, the porosity of the unidirectionally solidified sample should be proportional to square root of hydrogen partial pressure,

$$
p \propto a \sqrt{P_{\mathrm{H}_{2}}}
$$

where $p$ and $a$ denote porosity and proportional constant, respectively. The solid lines in Figs. 2(a) and (b) denote a function of square root of hydrogen partial pressure. The experimental data for Fig. 2(a) are well fit with the function. Since non-porous samples are formed under $10 \% \mathrm{H}_{2}-90 \% \mathrm{Ar}$ atmosphere, in the case of the samples fabricated using $15 \% \mathrm{SiO}_{2}-\mathrm{Al}_{2} \mathrm{O}_{3}$ feed rod, the experimental data for Fig. 2(b) are deviated from the fitting line. These results suggest that the hydrogen solubility gap decreases due to decreasing the hydrogen solubility of solid and liquid alumina by the silica addition.

Figure 3(a) and (b) show the cross section image parallel to the solidification direction for samples fabricated in $\mathrm{H}_{2}$ under the pressure of $0.8 \mathrm{MPa}$ using $99.99 \% \mathrm{Al}_{2} \mathrm{O}_{3}$ and $15 \% \mathrm{SiO}_{2}-\mathrm{Al}_{2} \mathrm{O}_{3}$ feed rods. In both cases, the cylindrical pores are elongated in the solidification direction. Obviously, 


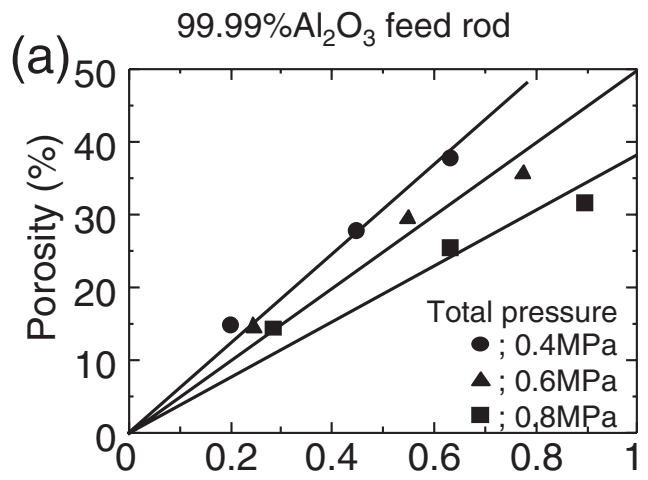

Hydrogen Partial Pressure, $\sqrt{P_{\mathrm{H}_{2}}} / \mathrm{MPa}^{0.5}$

$$
\text { (b) } 15 \% \mathrm{SiO}_{2}-\mathrm{Al}_{2} \mathrm{O}_{3} \text { feed rod }
$$

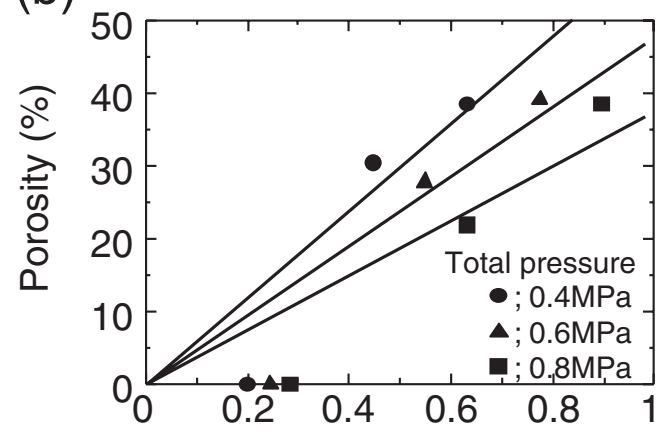

Hydrogen Partial Pressure, $\sqrt{P_{\mathrm{H}_{2}}} / \mathrm{MPa}^{0.5}$

Fig. 2 Porosity changes with hydrogen partial pressure (a) for the samples fabricated using $99.99 \%$ purity alumina feed $\operatorname{rod}^{5)}$ and (b) for the samples fabricated using $15 \% \mathrm{SiO}_{2}-\mathrm{Al}_{2} \mathrm{O}_{3}$ feed rod.

the number of pores for (b) is smaller than that of (a) and the pore diameter of (b) is larger than that of (a). Furthermore, from Fig. 2(a) and (b), the porosity of Fig. 3(b) is larger than that of Fig. 3(a). These results suggest another mechanism for pore growth is exist.
In addition to the large cylindrical pores, many facet shape small pores are also formed in the sample fabricated using $15 \% \mathrm{SiO}_{2}-\mathrm{Al}_{2} \mathrm{O}_{3}$ feed rod as shown in Fig. 3(b). When the solidification is performed in hydrogen atmosphere using silica added alumina feed rod, a small amount of vaporized material was deposited on inner wall of quartz tube. ${ }^{6}$ Figure 4(a) shows the X-ray diffraction pattern of the vaporized material. A broad pattern between $2 \theta=15$ and 30 degrees which is typical pattern for amorphous phase can be detected. The EPMA analysis of the vaporized material shows silica and alumina as shown in our previous report. ${ }^{6}$ In the $\mathrm{Al}_{2} \mathrm{O}_{3}-\mathrm{SiO}_{2}$ phase diagram, the primary phase for $15 \% \mathrm{SiO}_{2}-\mathrm{Al}_{2} \mathrm{O}_{3}$ composition is alumina phase and alumina and mullite phase appear below the solid line. However, no evidence for mullite phase can be detected in the powder Xray diffraction pattern of the solidified sample as shown in Fig. 4(b). All peaks in Fig. 4(b) can be indexed as $\mathrm{Al}_{2} \mathrm{O}_{3}$ phase. Since the small pores possess facet shape, it is considered that the pores are formed on the cooling step after the solidification. Hence, it is considered that the formation mechanism of the small pores is closely related to the vaporization of silica and alumina components from the solid phase. It is expected that the vaporization of silica component occurs on the inner wall of the cylindrical pores and the growth of the cylindrical pores is accelerated by the vaporization of silica component during the solidification.

\section{Conclusions}

To elucidate the mechanism of increase of porosity by silica addition, the unidirectional solidification of alumina with $15 \% \mathrm{SiO}_{2}$ was performed in pressurized hydrogen-argon mixed gases. The experimental results in the present study suggest that (1) the degree of easy forming of cylindrical pores decreases by silica addition due to decreasing hydrogen solubility in solid and liquid alumina phases and (2) the growth of the cylindrical pores is accelerated by the vaporization of silica component.
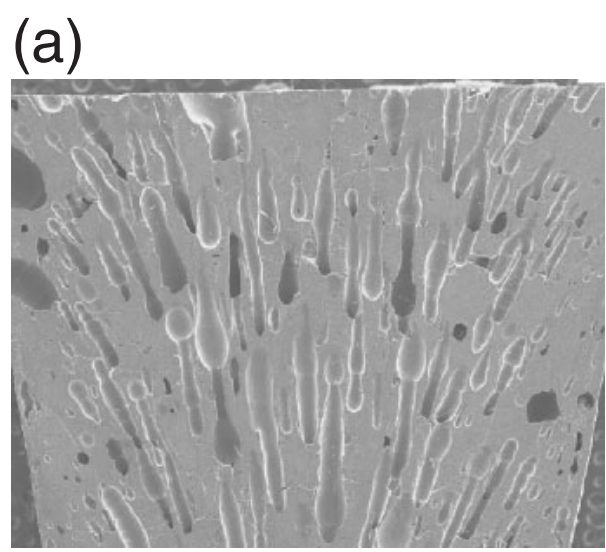

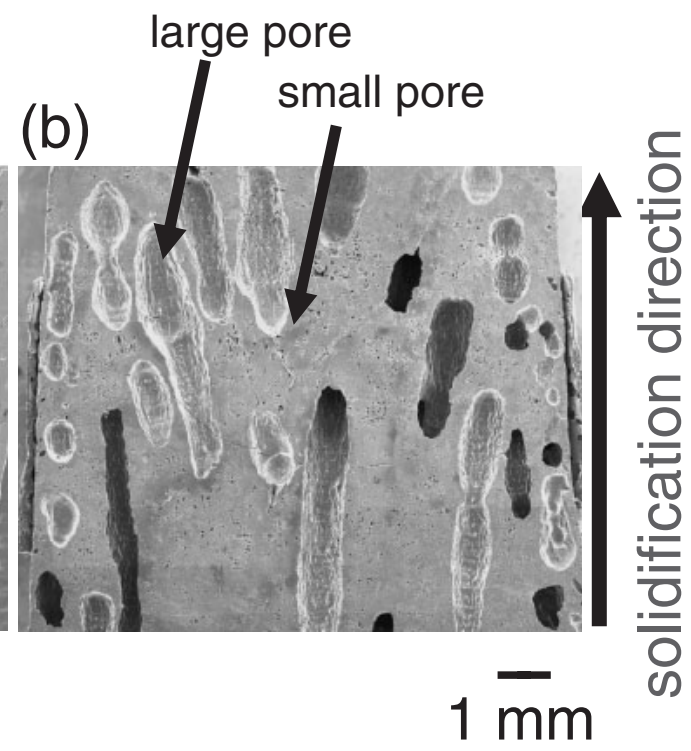

Fig. 3 Cross section parallel to the solidification direction of samples fabricated in $\mathrm{H}_{2}$ under the pressure of $0.8 \mathrm{MPa}$ using (a) $99.99 \% \mathrm{Al}_{2} \mathrm{O}_{3}$ and (b) $15 \% \mathrm{SiO}_{2}-\mathrm{Al}_{2} \mathrm{O}_{3}$ feed rods. 

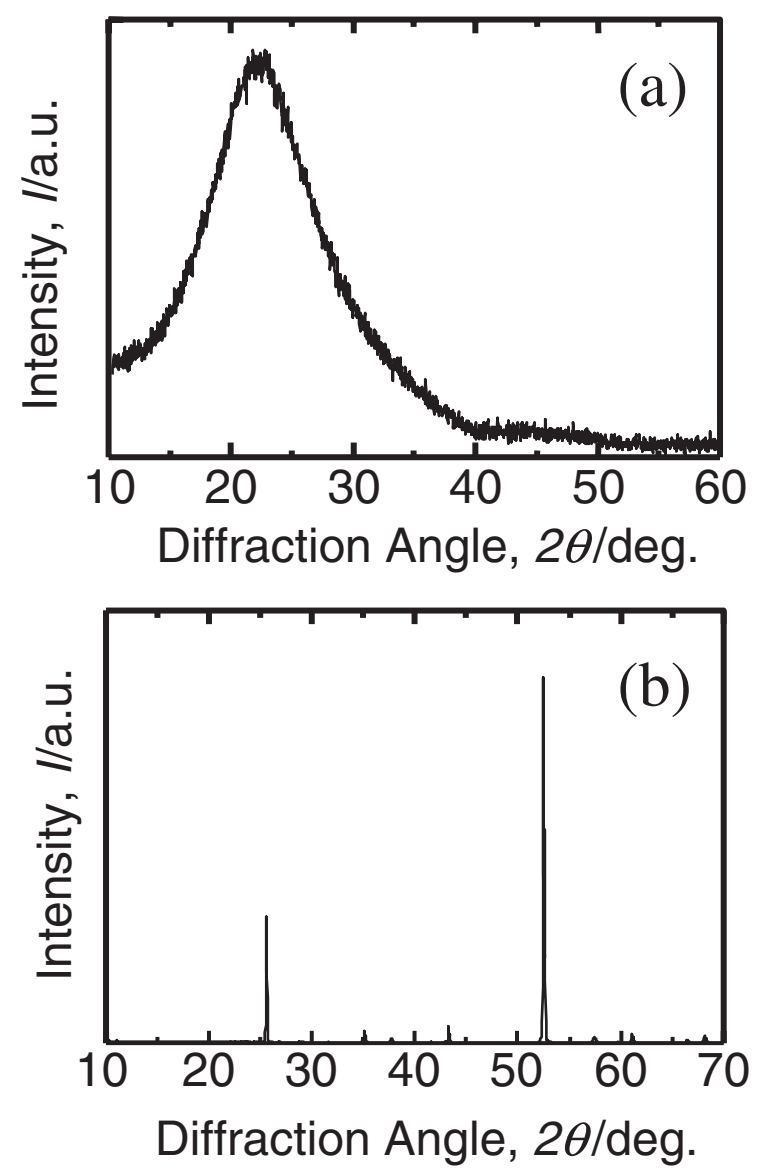

Fig. 4 Powder X-ray diffraction pattern of the vaporized material.

\section{Acknowledgements}

The present work was supported by Materials Science and Technology Research Center for Industrial Creation in Institute of Scientific and Industrial Research of Osaka University and by the Grant-in-Aid for Scientific Research (C) (No. 18560655) for the Japan Society for the Promotion of Science. The data of this paper was published in Japanese in Materia Japan 47 (2008) 399-405.

\section{REFERENCES}

1) K. Ishizaki, S. Komarneni and M. Nanko: Porous Materials: Process Technology and Applications, p. 6, Materials Technology Series, (Kluwer Academic Publishers, 1998).

2) G. J. Zhang, J. F. Yang and T. Ohji: J. Am. Ceram. Soc. 84 (2001) 13951397.

3) X. J. Ding, J. Z. Zhang, R. D. Wang and C. D. Feng: J. Eur. Ceram. Soc. 22 (2002) 411-414.

4) T. Isobe, T. Tomita, Y. Kameshima, A. Nakajima and K. Okada: J. Eur. Ceram. Soc. 26 (2006) 957-960.

5) S. Ueno, L. M. Lin and H. Nakajima: J. Am. Ceram. Soc. 91 (2008) 223-226.

6) S. Ueno, L. M. Lin, S. K. Hyun and H. Nakajima: Mater. Trans. 47 (2006) 2167-2171.

7) S. Ueno, L. M. Lin and H. Nakajima: J. Ceram. Soc. Jpn. 116 (2008) 137-140.

8) S. Ueno, L. M. Lin and H. Nakajima: Mater. Sci. Forum 569 (2008) 313-316.

9) E. Serra, A. C. Bini, G. Cosoli and L. Pillioni: J. Am. Ceram. Soc. 88 (2005) 15-18. 